\title{
Governança e financiamento do Projeto Calha Norte
}

Durbens Martins Nascimento - Professor do Departamento de Ciência Política da UFPA

\section{Resumo}

Este artigo expõe os resultados da pesquisa de doutoramento no âmbito do PDTU/NAEA/UFPA. Examina, sob a ótica da governança, o Programa Calha Norte (PCN), destinado a proteger e desenvolver a fronteira (Arco Norte) da Amazônia. A análise permite verificar que, a despeito das constantes crises de financiamento do Estado brasileiro ao longo da evolução do Projeto, isto é, de 1986 a 2002, as autoridades governamentais buscaram nutri-lo de condições mínimas de funcionamento, o que reflete o impacto das conjunturas críticas no desenvolvimento de políticas governamentais na Amazônia. Constata-se ainda que, a partir do final do segundo mandato do governo de Fernando Henrique Cardoso (FHC), em conseqüência da aplicação da Nova Política de Defesa Nacional (PDN), houve um aumento gradativo dos recursos públicos para financiar as ações na fronteira Norte, onde se instala o PCN, com aportes maiores de recursos na administração do presidente Luís Inácio Lula da Silva.

\section{Palavras-chave}

Projeto Calha Norte, Política de Defesa Nacional, financiamento, Amazônia.

\section{Abstract}

This article presents the results of a doctoral research project carried out at the PDTU/NAEA/UFPA graduate program. The research examined the "Calha Norte" Program (CNP), designed to protect and develop the Amazon border (North Arc), within a governance framework. Throughout the development of this project from 19862002, there were constant crises regarding its financing by the Brazilian state. In spite of this, such an analysis allows us to confirm that public authorities always tried to provide the minimal operational conditions for the project, therefore reflecting the impact of critical evaluations upon public policy development in the Amazon. From the end of the second term of President Fernando Henrique Cardoso (FHC), there was a gradual increase in public resources to finance actions in the Northern border region , where the CNP is located, resulting from the application of the New National Defense Policy (NDP). Increases in financial support has continued throughout the administration of President Luís Inácio Lula da Silva.

\section{Keywords}

Calha Norte Program, National Defense Policy, Financing, Amazon. 


\section{INTRODUÇÃO}

A Amazônia está na agenda mundial do debate sobre a defesa de suas fronteiras, consideradas largamente vulneráveis. A fronteira Norte, especialmente numa faixa de $150 \mathrm{~km}$ de largura e $7.413 \mathrm{~km}$ de extensão, definida constitucionalmente, situada ao norte das calhas dos rios Amazonas, Negro e Solimões e seus afluentes, Içá, Japurá, Branco, Uatumã, Jatapu, Nhamundá, Trombetas, Maicuru, Paru e Jarí, é uma área geográfica protegida pelo Programa Calha Norte (PCN). Internacionalmente, limita-se com as fronteiras políticas, no sentido de limites territoriais, da Guiana Francesa, do Suriname, da Guiana, da Venezuela e da Colômbia.

Aqui o governo brasileiro, em 1985, concebeu e implementou o PCN com o objetivo de garantir a presença do Estado e contribuir para a Defesa Nacional e a assistência às populações locais ${ }^{1}$. Esse objetivo do PCN altera-se no Plano Plurianual (PPA) 2000-2003, em que se acrescenta a frase "e fixando o homem na região", isto é, garantindo o desenvolvimento regional com a manutenção da soberania, entendida como espaço limitado, definido institucionalmente e administrado pelo Estado.

Recentemente, para toda a Amazônia Legal, o governo, na gestão de Fernando Henrique Cardoso (FHC), implementou o Sistema de Vigilância da Amazônia (SIVAM) - um sistema operacional formado a partir de uma rede de satélites e radares com o objetivo de vigiar o espaço aéreo da Amazônia Legal ${ }^{2}$, para produzir informações de diferentes naturezas e otimizar e agilizar a atuação dos órgãos estatais na

\footnotetext{
${ }^{1}$ No governo de Luís Inácio Lula da Silva, por meio da Exposição de Motivos n. ${ }^{\circ}$ 616, de 19 de dezembro de 2003, o PCN sofreu mudanças significativas na sua área de cobertura. Seu raio de ação foi estendido para os estados do Acre e Rondônia, o que provocou evidentemente uma alteração na área, na população e no número de municípios atingidos, que passou para 151, dos quais 95 na fronteira política, cobrindo uma área de 10.938 km. O PCN abrange, agora, 25\% do território nacional, com $2.186 .252 \mathrm{~km}^{2}$.

2 A Amazônia é concebida como um espaço não homogêneo, complexo e extremamente diversificado (GONÇALVES, 2001, p. 9). Nela há a Serra de Carajás, as planícies litorâneas, as florestas, sobretudo as frentes de expansão das relações sociais capitalistas e o "espaço vazio civilizatório", além das riquezas naturais, que devem ser controladas geopoliticamente pelo poder central, principalmente as situadas na Faixa de Fronteira. Mais do que isso: a Amazônia de que se fala é uma região que possui um vasto ecossistema de 6 milhões de $\mathrm{km}^{2}$, de base geomorfológica, pedológica, geológica, com fabulosas reservas de água doce e ocupação humana ao longo de sua história. Por outro lado, denomina-se Amazônia Legal a porção do território instituída pela Lei n. ${ }^{\circ}$ 1.806/1953, com 4,9 milhões de $\mathrm{km}^{2}$, o que representa $60 \%$ do território nacional e compreende os Estados do Amazonas, Pará, Rondônia, Roraima, Amapá, Acre, partes do Maranhão $\left(238.961 \mathrm{~km}^{2}\right)$, Tocantins e também parte de Mato Grosso $\left(875.720 \mathrm{~km}^{2}\right)$.
} 
região ${ }^{3}$. Ambos, PCN e SIVAM, no geral, têm a finalidade de defender, proteger e garantir a integridade do território nacional, combater os ilícitos e alavancar o desenvolvimento sustentado e sustentável. Registrese também que o discurso, tanto o dos principais documentos oficiais, quanto o das autoridades governamentais, salienta, exaustivamente, que o modelo da Nova Política de Defesa Nacional (PDN), expresso no PCN e no Projeto SIVAM, é singular, porque não causa degradação ambiental, não prejudica as nações indígenas e controla o processo de apropriação territorial por meio do manejo da questão agrária na Faixa de Fronteira. Tanto o PCN quanto o SIVAM integram o Sistema de Proteção da Amazônia (SIPAM), com sede em Manaus, ao qual estão subordinados. E situam-se em dois momentos da recente história republicana do país: a Transição (1985-1988) e a reforma de Estado (1992-2002), respectivamente.

O SIPAM é um sistema multidisciplinar que visa a coordenar as ações de vigilância na Amazônia, buscando integrar as diversas instituições públicas e privadas, a fim de gerenciar informações obtidas com os projetos para fins de segurança nacional e desenvolvimento social regional, reduzir custos infra-estruturais necessários ao desenvolvimento sustentável da região e alavancar a integração nacional, bem como aproveitar e garantir a biodiversidade e gerar bemestar para os habitantes, mediante políticas públicas na retórica governamental.

O estudo do financiamento do PCN à luz do conceito de governança exige a manipulação dos dados contidos no documento Segurança e Desenvolvimento, que fixa as fontes e o montante inicial para a implementação do Programa, no PPA 2000-2003, no Orçamento Público, na Lei de Diretrizes Orçamentárias (LDO) e no Avança Brasil. Tal

\footnotetext{
${ }^{3}$ Região, para usar uma expressão de Bourdieu (1989, p. 115), delimitada em função "dos diferentes critérios concebíveis (língua, habitat, tamanho da terra, etc.) [que] nunca coincidem". Esse sentido é tomado por diferentes autores: Amado (1990, p. 8) define região como uma categoria espacial que expressa uma especificidade, uma singularidade, dentro de uma totalidade. Assim, "a região configura um espaço particular dentro de uma determinada organização social mais ampla, com a qual se articula", isto é, a formação social concreta, cujo aspecto dinâmico e relevante é, para Silveira (1990, p. 35), "o nível de articulação das atividades produtivas da região com o modelo de acumulação dominante; na relação com os demais cortes espaciais, cujas 'fronteiras' estão em contínuo reajustamento, o aspecto básico é a forma específica de reprodução do capital, portanto, a diferenciação e articulação entre os cortes; e, finalmente, no âmbito interno à própria região, o aspecto básico é o nível de suas forças produtivas e suas relações de produção". Mas esses aspectos são também constituídos por relações políticas, ou seja, relações de poder que permeiam as relações sociais na região, que, na perspectiva da geografia, têm "um fundamento político, de controle e gestão de um território" (GOMES, 1995, p. 73).
} 
postura metodológica permitirá montar um esquema geral das condições de financiamento e da evolução do percentual em relação ao PIB e à dívida externa brasileira, a fim de realizar uma avaliação do que é destinado em cada momento dado, haja vista as críticas referentes à irracionalidade do Projeto, cujos benefícios estariam aquém dos custos. Para tanto, faz-se um levantamento anualmente do PIB, de 1986 a 2002, ao passo que, de 1986 a 1988, os dados são do documento Segurança e Desenvolvimento, que contém os valores dos três primeiros anos; já para o período de 1994 a 2002, são utilizadas informações da LDO, do PPA, do Orçamento de 1998 em diante e, finalmente, do Avança Brasil ${ }^{4}$.

Numa perspectiva histórica, aparentemente, o PCN representa um enorme custo para o contribuinte. Entretanto, ao invés de significar ineficiência do Estado na aplicação das verbas públicas, o PCN, a médio e a longo prazos, trará segurança e representará a diminuição da incerteza quanto aos riscos da perda da soberania brasileira sobre a Amazônia, evocada em um dos discursos em voga entre as autoridades militares e em segmentos da opinião pública. Em conseqüência, são quantias justificadas pelas demandas; os benefícios são desejados pela elite militar, que invoca a defesa territorial. Mais ainda: claramente, durante a reforma do Estado, no decurso do governo de FHC, apesar de alguns momentos críticos, houve uma recuperação dos investimentos, o que contrariava sensivelmente a idéia de que o Plano Real causou forte impacto na continuidade da segurança da fronteira política, especialmente.

As questões fundamentais que se colocam são as seguintes: Quais as implicações orçamentárias do PCN? Qual o significado da Nova PDN para o financiamento durante a administração de FHC (de 1994 a 2002)? Parte-se do pressuposto de que o Estado, dinamicamente, tem buscado controlar e proteger a Amazônia ao longo da história, e tem desempenhado o seu papel constitucional e político, com iniciativas e medidas preventivas no sentido de dissuadir quaisquer tentativas que expressem perigo para a manutenção da integridade territorial. Isso tem se refletido, recentemente na continuidade do PCN, cujo esvaziamento financeiro ocorreu menos ao programa governamental para ajustar as contas públicas durante a gestão de FHC e o pagamento da dívida externa do que a de tratá-lo secundariamente.

Ao mesmo tempo, temos razão para acreditar que a Nova PDN, implementada por aquele governo, impulsionou o revigoramento dos

${ }^{4}$ Cf. BRASIL, 2000, 2001, 2002a, 2002b. 
projetos de segurança e vigilância e fortaleceu a presença do Estado na fronteira política. A Nova PDN tentou ainda se adequar às transformações em curso regional e internacionalmente, decorrentes da substituição da ordem bipolar por uma ordem multipolar/unipolar. Nesse sentido, considerando-se as condições econômicas, políticas e sociais do Brasil e do cenário hemisférico no tocante à defesa e ao campo social - particularmente educação, habitação, saneamento e saúde -, cabe avaliar a necessidade de projetos que visem administrar a fronteira política, com base no modelo do desenvolvimento econômico-social sustentável.

Organizei o paper em cinco secções, além da Introdução e das Considerações Finais. A primeira ressalta a importância do conceito de governança e examina os planos e as peças orçamentárias do governo de Fernando H. Cardoso; a segunda secção descreve a estrutura do PCN e analisa o processo de alocação dos recursos financeiros para o projeto; as duas secções seguintes tratam da forma de distribuição dos recursos públicos durante as gestões dos presidentes José Sarney e Fernando H. Cardoso; a quinta e última secção avalia o impacto da Nova PDN no desenvolvimento das atividades do PCN.

\section{GOVERNO FHC: PPA, AVANÇA BRASIL E BRASIL EM AÇÃO}

Com o PPA, o Executivo visa instituir um plano estratégico de desenvolvimento do país a longo prazo. O PPA determina as condições institucionais para o planejamento das despesas e o financiamento das políticas públicas ${ }^{5}$. A LDO, por sua vez, é uma peça constitucional, na qual estão previstas as despesas e os investimentos para um período de um ano. A análise meticulosa dessas peças orçamentárias permite aferir o grau de comprometimento político da administração de FHC, enquanto ator político, com o financiamento de políticas públicas.

Quando se examinam esses veículos, constata-se que a forma de distribuição das provisões obedece a critérios políticos e técnicos. Desse modo, tanto o PPA quanto o Avança Brasil orientam-se pelas diretrizes da política macroeconômica. Considerando-se que essa política cultiva uma relação de cooperação econômico-financeira com os organismos de financiamento internacional, tais como o FMI e o BIRD, é de se esperar que nesses programas estejam presentes exigências desses organismos, contratualmente estipuladas. Uma dessas exigências dizia respeito ao

5 Por condições institucionais, entendem-se as circunstâncias que acompanham a organização das agências e instituições estatais encarregadas da produção e implementação de uma dada política pública, no interior de um determinado contexto sistêmico. 
cumprimento de metas para o superavit primário em relação ao PIB, no setor público.

O lançamento do Avança Brasil, agora denominado Brasil em Ação, deu-se num clima de euforia, com a reeleição de FHC. Por isso, o plano refletia o otimismo com que o governo pretendia resolver os impasses provocados pela vulnerabilidade externa da economia brasileira, atingida pela crise da economia mexicana. A estratégia adotada outra vez era a mesma: estabilização monetária a todo custo - às custas da recessão econômica provocada pelas altas taxas de juros praticadas no mercado -, a fim de captar financiamento externo para cumprir as obrigações fiscais e monetárias, isto é, equilibrar a balança de pagamentos.

O Brasil em Ação estabelecia intenções difíceis de serem alcançadas dadas as projeções baseadas em cálculos insustentáveis do crescimento do PIB nos quatro anos do segundo mandato do Presidente. As demandas dos militares por mais recursos estavam atreladas à possibilidade de desenvolvimento macroeconômico do país.

O orçamento da União define quanto o governo vai arrecadar com impostos e quanto vai gastar com investimentos e o custeio da máquina estatal. De sua análise, depreendem-se as relações existentes entre Estado e sociedade. A Constituição Federal ordena a primazia da Presidência na execução do Orçamento. O Presidente da República está obrigado a enviar ao Congresso o Projeto de Lei Orçamentária (PLO) até 30 de agosto; o Congresso, por sua vez, deve alterar e aprovar o projeto até 15 de dezembro.

As metas e diretrizes definidas pelo PPA e pela LDO são levadas em conta pelo Executivo ao elaborar o PLO. O PLO estima o total das receitas e fixa as despesas para o exercício fiscal subseqüente, ou seja, a proposta detalha programas e ações específicas, que devem estar de acordo com os dois instrumentos mencionados e deverão viger no ano seguinte.

A proposta é examinada pela Comissão Mista de Planos, Orçamentos Públicos e Fiscalização (CMPOF), sendo em seguida apreciada pelas duas Casas do Congresso: a Câmara e o Senado Federal. Posteriormente, o PLO é devolvido ao Executivo para sanção, com ou sem vetos (PEREIRA; MUELLER, 2002).

O artigo 165 da Constituição estabelece que cabe ao Executivo estimar as receitas e ao Congresso propor emendas, desde que sejam indicadas as fontes de receitas. Finalmente, é importante ressaltar que a Lei de Responsabilidade Fiscal limita a ação dos estados e municípios na medida em que fixa os gastos com pagamento de pessoal e investimentos públicos em 70\% do Orçamento das respectivas instâncias estatais. 


\section{ESTRUTURA E FINANCIAMENTO DO PCN}

Nesse sentido, o Orçamento é peça importante na discussão sobre a governança, que está associada, dentre outros aspectos, ao financiamento da reforma do Estado orientada para o mercado. É na reforma que a governança requer o reforço da autoridade das instituições políticas, um ordenamento institucional que define as articulações entre o público e o privado e o modus operandi das políticas públicas - como o governo identifica, produz, sustenta, monitora e implementa as políticas públicas, a fim de resolver os problemas da sociedade.

O debate sobre a governança resulta da crítica ao intervencionismo estatal e do estabelecimento de novas relações entre o Estado e a sociedade, o mercado e o cidadão. A função do Estado é agir eficientemente para alcançar objetivos definidos por autoridades investidas em cargos eleitorais e por agentes públicos que, graças a prerrogativas emanadas da Constituição, exercem funções técnicas que vão além de um mandato eleitoral, por serem carreiras de Estado. A governança diz respeito, portanto, a um conjunto de instituições organizadas para ampliar a participação da soicedade e tornar eficaz o processo de gestão pública.

É importante frisar que nessa concepção, o Estado, ainda que busque reduzir os custos no exercício de suas atividades, apresenta-se como articulador e promotor do desenvolvimento e agente da modernização econômica. Por isso, qualquer discussão sobre as políticas públicas, ainda mais aquelas destinadas a fortalecer a segurança, exige, obviamente, a análise dos aspectos políticos que conformam o jogo da disputa por recursos do orçamento público.

A análise dos aspectos políticos é importante por duas razões. Em primeiro lugar, para os reformistas, o Estado deve ser capaz de elaborar políticas públicas eficazes, atingir suas metas a um custo reduzido, sem prejuízo da qualidade operacional. Isso implica a capacidade estatal de dotar, no caso da PDN, as Forças Armadas (FFAA) de equipamentos tecnológicos e informacionais de última geração, para assegurar a vigilância. Em segundo lugar, como diria um especialista, o gasto público realizado por uma dada escala de governo, num conjunto fixo de políticas públicas, num dado ano fiscal, expressa com relativa precisão as preferências alocativas dos atores sociais (REZENDE, 1997). 


\section{RECURSOS DESTINADOS AO PCN NA GESTÃO DE JOSÉ SARNEY (1986-1990)}

No documento Desenvolvimento e Segurança (BRASIL, 1985), constata-se que as quantias previstas são exclusivamente públicas. Essas quantias dividem-se conforme os programas, e seus valores mudam de acordo com a ação específica correspondente. As verbas são administradas pelos ministérios militares - Exército, Marinha e Aeronáutica -, pelo Ministério da Fazenda, pelo Ministério do Interior (MINTER), pelo Ministério das Relações Exteriores (MRE), e por órgãos específicos, responsáveis pela execução de políticas setoriais, como a Fundação Nacional do Índio (FUNAI) e as Comissões de Demarcação de Limites.

Os recursos eram garantidos pela Secretaria de Planejamento (SEPLAN) durante a crise econômica e social pela qual passou a sociedade em 1985 e 1986. Mas essa crise não impediu que se determinasse como prioridade de governo a execução imediata do Projeto Calha Norte. O exame detalhado das cifras destinadas a esse projeto revela que, apesar da mudança de regime político - que passou de um regime autoritário para uma democracia, de um governo militar para um civil -, dada a concórdia entre os principais atores do processo político brasileiro, que tentavam impedir uma radicalização de determinados grupos políticos, marcados ideologicamente e perseguidos pelo regime militar durante os anos de chumbo, permaneceu inalterada a vontade dos quartéis para a Amazônia brasileira.

Para o período de 1986 a 1990, foram previstos Cz\$ 628.892 milhões, o que, para valores de 2002, chega a US\$ 92.645 milhões. De acordo com Oliveira Filho (1990, p. 20), esses recursos foram distribuídos da seguinte forma no decorrer de cinco anos, como ilustra o planejamento contido no documento anteriormente mencionado: 35,1\% (1986), 40,2\% (1987), 12,4\% (1988), 6\% (1989) e 6,3\% (1990).

O governo concentrou os investimentos nos dois primeiros anos, o que reflete a intensidade da forma de aplicação do PCN. Outro aspecto a destacar é o seu conteúdo notoriamente afinado com o Exército, que obtém o máximo do dinheiro reservado, o que faz desse órgão o responsável direto pelo êxito do PCN. Dos órgãos de governo da área da defesa, a Marinha recebeu apenas Cz\$134.354 milhões; no conjunto dos ministérios, contudo, a menor quantia foi destinada ao MRE - Cz\$13.351 milhões.

No geral, realmente, dadas as prioridades orçamentárias, concluise que se investia pesadamente na presença militar, bem como numa arrojada política indigenista para a região, o que é revelado pelas somas aplicadas na reestruturação da FUNAI, no âmbito do Ministério do Interior. Significativamente, priorizou-se a delimitação e a localização 
de áreas indígenas, e não, como os defensores das comunidades Yanomami fizeram crer, essa etnia, apesar dos Cz\$ 24.190 milhões. A concepção de ocupação militar para a defesa das fronteiras políticas não previa um paradigma de desenvolvimento, ou, se previa, o paradigma adotado era o dos grandes projetos em andamento na época. De fato, ao contrário do que constaria nas décadas posteriores, são insignificantes os valores aplicados no desenvolvimento local por meio de projetos de incentivo a atividades produtivas comunitárias, embora o governo, nas administrações de José Sarney, Fernando Collor de Melo e Itamar Franco, tivesse aplicado no PCN o montante de US\$140.122 milhões. Por fim, destacam-se mudanças importantes no processo e na execução do PCN na gestão de FHC.

\section{FINANCIAMENTO DO PCN NA GESTÃO DE FHC (1995-2002)}

A nova equipe que assumiu em janeiro de 1995 cumpria uma plataforma político-econômica de estabilidade monetária, com ajustes nas contas públicas, redução dos gastos governamentais, privatização de empresas públicas, abertura comercial e financeira da economia e desregulamentação das relações trabalhistas para priorizar as parcerias mediante contratos coletivos de trabalho, num novo paradigma jurídico para o setor.

Uma avaliação ampla dos aspectos políticos, tanto negativos quanto positivos, do governo FHC é incompatível com os objetivos deste paper. Pode-se dizer, porém, que, em oito anos, o governo enfrentou diversas turbulências internacionais, destando-se as crises das economias latinas - México em 1994, Argentina e Brasil no primeiro semestre de 1997 -, asiáticas - Cingapura, Malásia, Taiwan e Coréia em 1997 - e russa (em 1998). Além disso, as relações interestatais estiveram conturbadas com a guerra separatista na Iugoslávia, a guerra do Golfo, a guerra da Somália e a invasão do Afeganistão. Do ponto de vista do desenvolvimento, ainda pensado nos moldes tradicionais, foi um período de fraco desempenho das economias industrializadas, com estagnação e depois recuperação da economia norte-americana. Regionalmente, vale o registro de que somente o Chile cresceu no continente.

No aspecto social, o desemprego atingiu índices alarmantes no mundo inteiro, quer por causas estruturais, quer por fatores conjunturais, como a necessidade de flexibilização das relações de trabalho e a mudança no paradigma da estruturação do trabalho engendrada pela inovação tecnológica. Tudo isso teve impacto nas políticas públicas dos 
países em geral e no Brasil, em particular. Aqui houve o agravante das privatizações e da resistência dos setores recém-criados com a terceirização na economia à absorção do contingente de desempregados, além do conseqüente crescimento da informalidade. Mas é preciso ressaltar que o governo central logrou êxito no combate à inflação e no ajuste das contas públicas, com o Plano de Estabilização Monetária (PEM) e a modernização do gerenciamento de algumas agências prestadoras de serviços públicos. Em suma, o governo teve de administrar as ocupações de fazendas pelo Movimento dos Trabalhadores Sem Terra (MST), as greves dos servidores públicos federais e, sobretudo, o movimento em defesa das empresas estatais.

Nesse quadro adverso, o governo teve de lidar com a capacidade reguladora do Estado, compatibilizando uma economia aberta com políticas públicas em áreas onde o mercado não promove a eficiência a curto e a longo prazo, a fim de manter a governança por meio do funcionamento eficiente das instituições políticas e, no segundo mandato, de um ousado plano de constituição de agências reguladoras dos serviços públicos, pensados como um novo paradigma da relação do Estado com o cidadão.

É nesse contexto de mudanças e alterações na gestão pública do Estado que a segurança nacional altera sua gestão assim como sua política de defesa: em 1996, é lançada a Nova PDN (1996); em 1997, é revitalizado o PCN, que se transforma em programa a partir de 2000 e se torna prioridade de defesa por iniciativa do então Ministro da Defesa, Geraldo Quintão, em 2001; por fim, não menos importante, é criado o Ministério da Defesa em 1999.

Investiram-se no PCN, até 2002, US\$181.188 milhões. Durante o período de 1995 a 2002, os valores aplicados totalizaram US\$41.066 milhões, contra US\$140.122 milhões no período anterior, isto é, de 1986 a 1994. A média desse último período é de US\$ 15.569 milhões anuais. Em contrapartida, aplicaram-se em média, no governo reformista, US\$ 5.133 milhões. Embora esse valor seja baixo, é preciso considerar que, quando o Presidente assumiu, o PCN estava implementado, como previsto no cronograma anterior, e os custos seguintes deviam-se à manutenção da máquina burocrática e dos equipamentos de infra-estrutura disseminados na fronteira política.

Para a presente análise, importa comparar o PIB, a Dívida Externa Líquida (DEL) e os investimentos em termos quantitativos que figuram no orçamento da Defesa, com a finalidade de mensurar a responsabilidade do governo na paralisia orçamentária (ver Tabelas 1 e 2). 
Tabela 1: População residente e PIB/Brasil - 1992-2000.

\begin{tabular}{l|c|c|c}
\hline Ano & População residente & $\begin{array}{c}\text { PIB } \\
\text { Total }(1.000 .000 \mathrm{R} \$)\end{array}$ & Per capita R $\$$ \\
\hline 1992 & 152.226 .988 & 840.537 & 5.552 \\
\hline 1993 & 154.512 .692 & 881.930 & 5.708 \\
\hline 1994 & 156.775 .230 & 933.548 & 5.955 \\
\hline 1995 & 159.016 .334 & 972.955 & 6.119 \\
\hline 1996 & 161.247 .046 & 998.861 & 6.194 \\
\hline 1997 & 163.470 .521 & 1.031 .556 & 6.310 \\
\hline 1998 & 165.687 .517 & 1.032 .928 & 6.234 \\
\hline 1999 & 157.909 .738 & 1.041 .267 & 6.202 \\
\hline 2000 & 170.143 .121 & 1.086 .700 & 6.387 \\
\hline
\end{tabular}

Tabela 2: Demonstrativo comparativo do PIB, da dívida externa e dos investimentos no PCN.

\begin{tabular}{|c|c|c|c|c|c|c|c|c|c|c|}
\hline \multirow[t]{2}{*}{ Anos } & \multicolumn{2}{|c|}{ PIB } & \multicolumn{3}{|c|}{$\begin{array}{l}\text { Dívida externa } \\
\text { milhões US\$ }\end{array}$} & & \multirow{2}{*}{$\begin{array}{c}\text { DEL/ } \\
\text { PIB } \\
\% * *\end{array}$} & \multicolumn{3}{|c|}{$\begin{array}{c}\text { PCN = US\$ } \\
\text { milhões/2003 }\end{array}$} \\
\hline & $\begin{array}{l}\text { Milhões } \\
\text { US\$ }\end{array}$ & $\begin{array}{c}\text { Taxa/ } \\
\text { cresc. } \\
\text { real }\end{array}$ & DEL & $\begin{array}{c}\text { Desem- } \\
\text { bolso }\end{array}$ & Juros & $\begin{array}{l}\text { Amor- } \\
\text { tização }\end{array}$ & & PCN & $\%$ & \% PIB \\
\hline 1986 & 257,810 & 7,5 & 101.759 & 13.232 & 13.072 & 10.245 & 39,5 & 14.120 & 13,8 & 5,4 \\
\hline 1987 & 282,360 & 3,5 & 107.759 & 11.973 & 13.630 & 9.319 & 38,1 & 14.916 & 13,8 & 5,2 \\
\hline 1988 & 205,710 & $-0,1$ & 102.555 & 15.470 & 17.049 & 10.591 & 49,9 & 16.298 & 15,8 & 7,9 \\
\hline 1989 & 415,920 & 3,2 & 99.285 & 31.326 & 34.688 & 10.937 & 23,8 & 47.311 & 47,6 & 11,3 \\
\hline 1990 & 469,318 & $-4,3$ & 96.546 & 4.143 & 8.778 & 10.868 & 20,5 & 16.357 & 16,9 & 3,4 \\
\hline 1991 & 405,679 & 1,0 & 92.996 & 5.827 & 7.721 & 9.493 & 22,9 & 9.652 & 10,3 & 2,3 \\
\hline 1992 & 387,295 & $-0,5$ & 110.835 & 27.304 & 8.402 & 8.278 & 28,6 & 9.261 & 8,3 & 2,3 \\
\hline 1993 & 429,685 & 4,9 & 114.270 & 12.355 & 9.711 & 9.329 & 26,5 & 5.616 & 4,9 & 1,3 \\
\hline 1994 & 543,087 & 5,9 & 119.668 & 54.651 & 46.158 & 8.140 & 22,0 & 6.591 & 5,5 & 1,2 \\
\hline 1995 & 705,449 & 4,2 & 129.313 & 17.429 & 10.409 & 10.427 & 18,3 & 4.798 & 3,7 & 0,6 \\
\hline 1996 & 775,475 & 2,7 & 144.092 & 25.867 & 13.754 & 12.389 & 18,5 & 2.950 & 2,0 & 0,3 \\
\hline 1997 & 807,814 & 3,3 & 167.760 & 45.768 & 25.235 & 13.500 & 20,7 & 4.063 & 2,4 & 0,5 \\
\hline 1998* & 787,889 & 0,1 & 220.350 & 61.048 & 29.791 & 15.321 & 27,9 & 3.912 & 1,7 & 0,4 \\
\hline 1999 & 536,554 & 0,8 & 203.338 & 40.557 & 45.437 & 17.100 & 37,8 & 676 & 0,3 & 0,1 \\
\hline 2000 & 602,207 & 4,4 & 196.179 & 37.319 & 31.977 & 17.096 & 32,5 & 10.084 & 5,1 & 1,6 \\
\hline 2001 & 510,360 & 1,4 & 192.720 & 34.624 & 35.151 & 17.621 & 37,7 & 5.533 & 2,8 & 1,0 \\
\hline 2002 & 451,005 & 1,5 & 195.587 & 18.594 & 31.025 & 15.275 & 43,3 & 9.050 & 4,6 & 2,0 \\
\hline Total & 8.573 .617 & - & 2.395 .012 & 457.487 & 381.988 & 205.929 & 27,9 & 181.188 & 7,5 & 2,1 \\
\hline
\end{tabular}

Fonte: Banco Central do Brasil (BACEN)/Departamento Intersindical de Estatísticas e Estudos Socioeconômicos (DIEESE).

* A crise no mercado mundial resultou na redução do PIB, em dólares, em 1998 e 1999, devido à flexibilização cambial de 1999.

** DEL. 
Infere-se da comparação, em primeiro lugar, que os recursos aplicados são insignificantes em relação à importância da proteção da extremidade Norte, se comparado com o despendido em desembolso, juros e amortizações da dívida externa, como mostram as Tabelas 1 e 2. Outro aspecto a destacar é que, embora o PIB de 1990 fosse o maior dos anos definidos, a participação do PCN é bastante reduzida, apesar de concentrada nos quatro primeiros anos, isto é, de 1986 a 1990.

Em segundo lugar, observa-se que as liberações de recursos financeiros, para as atividades do PCN e custear a máquina burocrática instalada na fronteira, concentraram-se em 1989. Convém lembrar que, de acordo com o planejamento inicial contido no documento Desenvolvimento e Segurança, naquele ano, seriam liberados 6,0\% do total da verba. Ora, os dados revelam que isso não ocorreu. Na verdade, dadas as vicissitudes da economia brasileira e as contingências sociais e políticas, o desbloqueio das verbas no ano de 1989 chegou a 47,6\%, para o período analisado, isto é, de 1986 a 1990.

O mais importante da análise da Tabela 2 diz respeito ao problema da relação entre o PIB, a dívida externa e os recursos destinados ao Programa. Em 1997, portanto durante o mandato de FHC, o PIB bate recorde, com US\$ 807,814 milhões, quatro vezes mais do que em 1988. De 1990 a 1999, o governo reduz drasticamente os meios financeiros destinados ao Projeto até o limite de US\$ 676 mil dólares, nessa espécie de década perdida para o PCN.

Interpretando-se o conjunto da Tabela 2 , verifica-se que há uma relação entre o PIB e a DEL; por outro lado, nada indica que exista uma relação com o PCN. De fato, um conjunto de pesquisas na área das ciências sociais tem demonstrado que o pagamento da dívida externa condiciona a aplicação dos meios financeiros em vários programas governamentais (isso não tem a ver com a ideologização do debate sobre o tema, tampouco há espaço para refletir sobre suas implicações sociopolíticas). No caso concreto, há evidências de que aquela relação não implicou o contingenciamento de recursos, a não ser em 1999, com a clara crise dos mercados financeiros internacionais, que atingiu sobremaneira a economia brasileira, como se verá a seguir.

De 1986 a 1997, o PIB cresce paulatinamente, com exceção de 1992, quando interrompe essa trajetória. Embora os investimentos no PCN tenham se recuperado em 2000, ele continua em queda livre em relação ao pagamento da dívida externa, apesar da líquida ter sido reduzida em função da renegociação com os credores internacionais. Em conseqüência, não se pode afirmar que a redução das aplicações orçamentárias seja resultado da queda do PIB, porque, no momento, em 2000 e 2002, os investimentos aumentam, e ele continua em declínio. Conclui-se que outras razões que transcendem às relações econômicofinanceiras explicam a crise de financiamento do Projeto. 
A hipótese da determinação política do governo é plausível, pois a defesa da Amazônia faz parte das prioridades governamentais. Se não for essa a razão, como explicar que tanto no início do governo de José Sarney, quanto no final do mandato de FHC, apesar da crise social e econômica, da queda do PIB - respectivamente, três vezes e duas vezes abaixo do de 1997, calculado nominalmente - e da dívida externa média de 38,8 em 1986 e em 1987, no governo do Presidente José Sarney, e de 40,5 em 2001 e em 2002, no governo seguinte -, os recursos aumentaram nos primeiros anos do governo Sarney e nos últimos anos do governo FHC, em vez de diminuírem, como seria lógico?

A decisão política de marginalizar o PCN poderia ser motivada pela verba exorbitante destinada à defesa? A análise do PIB e do Orçamento Público com relação à defesa poderá trazer uma resposta a essa pergunta.

Comparar os gastos em defesa no Brasil com os dos países da América do Sul e particularmente com os daquelas sociedades que se assemelham no que diz respeito à economia, aos bens naturais e genéticos, à população e à extensão territorial, como EUA, Rússia, China e Índia, é a postura analítica que se adotará para situar e aferir a posição do Brasil no sistema internacional e em relação a seus vizinhos na América do Sul. É evidente que a geopolítica contemporânea não reduz o cálculo estratégico somente a essas variáveis. Por exemplo, a biodiversidade, os estoques de água, os novos materiais, a tecnologia de ponta e a informação são considerados relevantes para a mensuração do poder e da influência no concerto das nações. Contudo, é evidente que aqueles fatores ainda preservam seu valor geopolítico.

Entre os chamados monster countries, com vantagens comparativas suficientes para ter pretensões hegemônicas, o Brasil é o que investe insuficientemente para manter uma nação desse porte em condições de enfrentar os desafios de cenários conturbados, ainda que não se vislumbrem ameaças concretas no hemisfério sul.

Tabela 3: Despesas militares e PIB dos maiores países em população, território e recursos -2002 .

\begin{tabular}{l|c|c|c}
\hline Países & $\begin{array}{c}\text { PIB* }=\text { US\$ } \\
\text { trilhões }\end{array}$ & $\begin{array}{c}\text { Defesa } \\
\text { bilhões }\end{array}$ & $\%=100$ \\
\hline EUA & 10,4 & 276,7 & 3,2 \\
\hline Rússia & 1,35 & - & - \\
\hline China & 5,7 & 55,91 & 2,3 \\
\hline Índia & 2,66 & 11,52 & 1,9 \\
\hline Brasil & $1,34^{* *}$ & 13,408 & 2 \\
\hline
\end{tabular}

Fonte: Centro de Estudios Nueva Mayoría. Disponível em: http://www.nueva mayoria.com. 

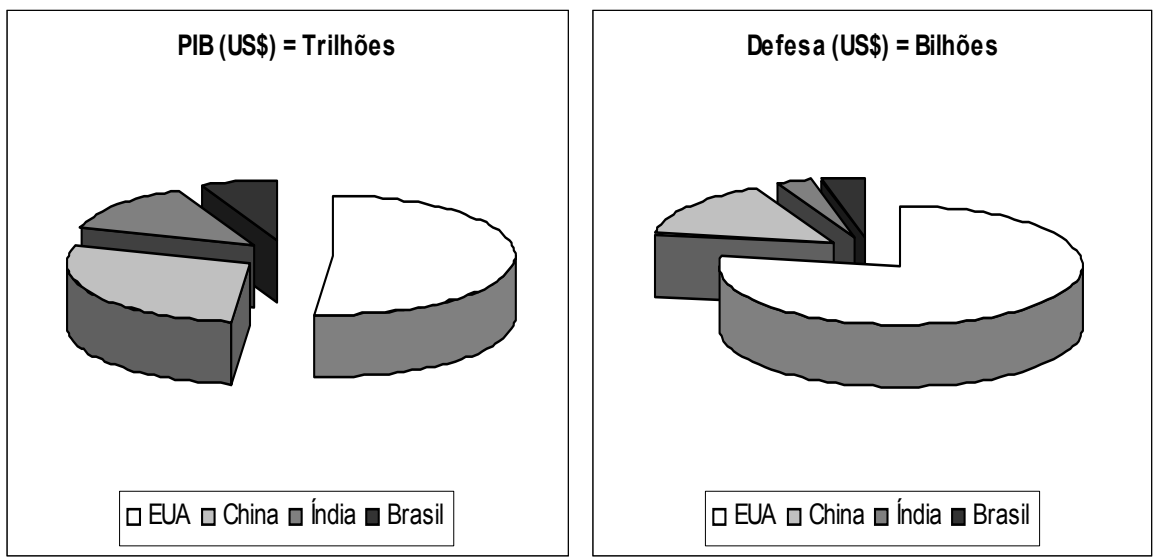

Gráfico 1: Comportamento das despesas militares e do PIB dos maiores países em população, território e recursos - 2002.

Fonte: Centro de Estudios Nueva Mayoría. Disponível em: http://www.nueva mayoria.com.
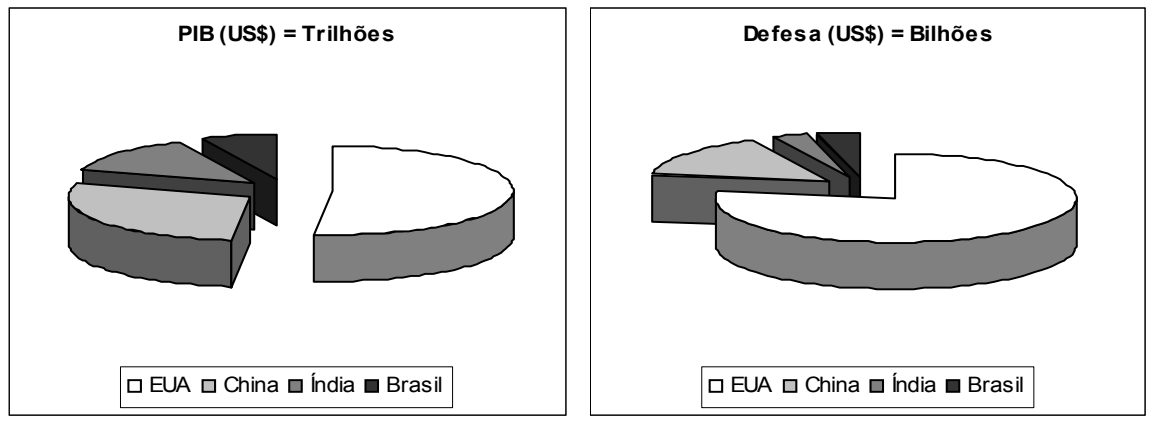

Gráfico 2: Despesas militares dos países maiores em população, território e recursos - 2002.

Fonte: Centro de Estudios Nueva Mayoría. Disponível em: http://www.nueva mayoria.com.

Em termos absolutos, os EUA são, de longe, o país que gastam mais em defesa (Tabela 3 e Gráficos 1 e 2). São nada menos que US\$ 276,7 bilhões aplicados internamente e no exterior, com a manutenção de um arsenal convencional de 250.000 militares no mundo inteiro e 7.500 armas nucleares a um custo de 30 bilhões de dólares (KORB, 1999, p. 9). Podem fazer isso porque têm o maior PIB do mundo, com um pouco mais de US\$10 trilhões, e precisam exercer a supremacia no 
concerto das nações contemporâneas. Em contraste, a República Popular da China, no tocante à relação PIB/Gastos Militares, é quem lidera o ranking mundial no setor. A China investiu, em 2002, um total de US\$ 55,91 bilhões. Esse valor representa 4,3\% do PIB, o que é o maior percentual do mundo. Basta consultar a Tabela 3 para constatar que a média de gastos em relação ao PIB dos países ricos que compõem o G-7 é de $2,0 \%$, e o conjunto dos países industrializados aplica 2,2\%, embora, relativamente por região do planeta, o Oriente Médio mais a Turquia registrem um índice superior em relação ao PIB - 6,6\%. Por fim, a Tabela 4 revela que a América Latina e o Caribe são as regiões que menos gastam com defesa nacional. O Brasil investe apenas 1,15\% do PIB mesmo assim o maior orçamento da região.

Tabela 4: Gastos em defesa em percentagem do PIB para o ano de 2002.

\begin{tabular}{l|c}
\hline Regiões/países & $\begin{array}{c}\text { Gasto militar } \\
\text { em \% do PIB }\end{array}$ \\
\hline Todos os países & 2,6 \\
\hline Economias desenvolvidas & 2,2 \\
\hline Países mais industrializados (G-7) & 2,0 \\
\hline Outras economias desenvolvidas & 2,3 \\
\hline Países asiáticos de industrialização emergente & 3,6 \\
\hline Economias em desenvolvimento & 3,3 \\
\hline África & 3,2 \\
\hline Ásia & 3,2 \\
\hline Oriente Médio e Turquia & 6,8 \\
\hline América (sem EUA e Canadá) & 1,6 \\
\hline Economias em transição & 2,5 \\
\hline Europa Central e Oriental & 2,4 \\
\hline
\end{tabular}

Fonte: CENTRO de Estudos Nueva Mayoría. Disponível em: <http:// www.nuevamayoria.com>.

A Tabela 5 e o Gráfico 3 mostram que o Brasil é, ao lado da Argentina, o que mais despende recursos em defesa na América do Sul. Todavia, as FFAA e o setor da defesa em conjunto são os que menos recebem recursos, considerando-se o estritamente aplicado nas questões ligadas ao setor: treinamento, operações de rotina, tecnologia, equipamentos etc. As próprias autoridades incluem, equivocadamente, nos gastos militares a seguridade social, que é de responsabilidade dos Ministérios Militares (agora Ministério da Defesa) depois da Constituição de 1988, bem como o pagamento de pessoal, incluindo ativos, inativos e pensionistas. Aliás, as filhas de militares tinham direito a uma pensão vitalícia 
desde o fim da Guerra do Paraguai, mas esse benefício foi cortado na última reforma da Previdência Social (2003).

Para a análise comparativa, selecionou-se no Executivo, o Ministério da Defesa, cujo gasto com pessoal e encargos sociais é enorme, e outros dois órgãos - o Ministério da Fazenda (segundo valor) e a Secretaria de Desenvolvimento Urbano (menor); no Judiciário, a Justiça do Trabalho, que concentra os maiores recursos nessa categoria; finalmente, a Câmara dos Deputados, no Poder Legislativo. O resultado da comparação entre esses órgãos não é nada animador. A Defesa, isoladamente, dispõe de uma verba três vezes maior do que a do segundo órgão da República para financiar pessoal e encargos sociais. Ao mesmo tempo, suas metas são amplas: investe, por exemplo, na reforma de escolas e de outros equipamentos sociais relacionados com o processo de constituição dos aparelhos urbanos na fronteira política. Isso mostra a dificuldade de se saber o que, efetivamente, é gasto militar, embora seja gasto com a defesa numa concepção ampla.

Tabela 5: Gastos no setor militar dos países da América do Sul para o ano de 2002.

\begin{tabular}{l|c|c}
\hline Regiões/países & $\begin{array}{c}\text { Gastos militares } \\
=\text { milhões US\$ }\end{array}$ & $\begin{array}{c}\text { Total/ } \\
\text { percentual \% }\end{array}$ \\
\hline Total global & 842.717 & 100 \\
\hline Argentina & 1.386 & 0,16 \\
\hline Brasil & 9.651 & 1,15 \\
\hline Uruguai & 212 & 0,03 \\
\hline Paraguai & 54 & 0,01 \\
\hline Total Mercosul & 11.303 & 1,34 \\
\hline Bolívia & 119 & 0,01 \\
\hline Chile & 2.557 & 0,30 \\
\hline Colômbia & 2.840 & 0,34 \\
\hline Equador & 685 & 0,08 \\
\hline Guiana & 5 & 0,00 \\
\hline Peru & 865 & 0,10 \\
\hline Suriname & 8 & 0,00 \\
\hline Venezuela & 1.081 & 0,13 \\
\hline Total resto da América do Sul & 8.160 & 0,97 \\
\hline Total América do Sul & 19.463 & 2,31 \\
\hline
\end{tabular}

Fonte: Centro de Estudios Nueva Mayoría. Disponível em: http://www.nueva mayoria.com. 


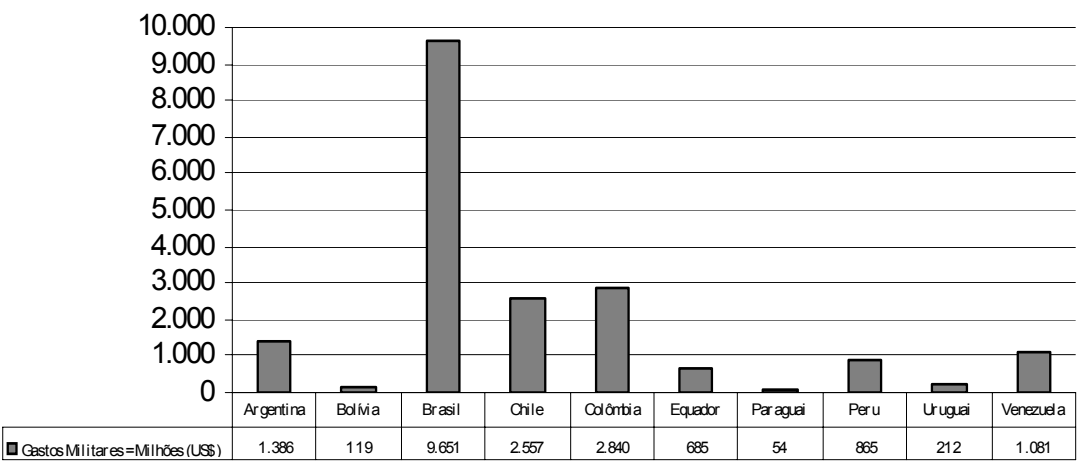

Gráfico 3: Gastos no setor militar dos países da América do Sul para o ano de 2002 .

Fonte: Centro de Estudios Nueva Mayoría. Disponível em: http://www.nueva mayoria.com.

Tabela 6 - Despesas com Pessoal e Encargos Sociais/ R\$ Mil

\begin{tabular}{l|c|c|c}
\hline Ministério & 2000 & 2001 & 2002 \\
\hline Total nacional & 51.930 .700 & 59.200 .000 & 68.497 .793 \\
Executivo & & & \\
Defesa Fazenda & $\begin{array}{c}15.120 .654 \\
\text { Secretaria de Des. Urbano }\end{array}$ & $\begin{array}{c}18.725 .111 \\
4.978 .552 \\
1.491\end{array}$ & $\begin{array}{c}20.568 .009 \\
1.893\end{array}$ \\
& & & 1.574 \\
\hline Judiciário & 3.791 .775 & 4.251 .334 & 4.296 .503 \\
Justiça do Trabalho & & & \\
\hline Legislativo & 983.852 & 1.168 .088 & 1.407 .582 \\
\hline Câmara dos Deputados &
\end{tabular}

Fonte: BRASIL. Congresso Nacional. Lei n. ${ }^{\circ}$ 10.524, de 25 de julho de 2002, inciso IV, do Anexo das Informações Complementares ao Projeto de Lei Orçamentária de 2003.

Todavia, quando se comparam as despesas do orçamento dos órgãos de governo (ver Tabelas 6 e 7), verifica-se facilmente que o orçamento da Defesa representa 4,0\% do cômputo geral. Perde para a Previdência Social e a Saúde. Constata-se que certamente o peso dos gastos com pessoal e encargos sociais é significativo, o que deixa o setor em desvantagem para reivindicar a elevação do teto da dotação orçamentária, em virtude das outras prioridades da sociedade brasileira. É certo que, em países onde o sistema de direitos sociais mais avançou, com um amplo e seguro programa de bem-estar - não é o caso do Brasil -, normalmente a educação, a saúde e a seguridade social são aquinhoadas com elevadas somas do Orçamento Público. 
Tabela 7: Orçamento de despesas dos principais ministérios do Governo.

\begin{tabular}{l|c|c}
\hline Órgão/Ministério & 2002 & $\%$ \\
\hline Total do Orçamento & 650.409 .519 & 100 \\
\hline Agricultura e Pecuária e & 5.184 .948 & 0.8 \\
Abastecimento & & \\
\hline Educação & 17.421 .384 & 2.6 \\
\hline Previdência e Assistência Social & 95.211 .730 & 14.6 \\
\hline Saúde & 28.551 .445 & 4.3 \\
\hline Defesa & 26.205 .556 & 4.0 \\
\hline Integração Nacional & 6.835 .045 & 1.0 \\
\hline Demais & 470.999 .411 & 72.4 \\
\hline
\end{tabular}

Fonte: BRASIL. Governo Federal. Ministério do Planejamento. Orçamento do ano de 2002. Disponível em: < http://www.planejamento.gov.br> . Acesso em: 22 abr. 2003.

Tabela 8: Recursos aplicados mediante parcerias com prefeituras.

\begin{tabular}{c|c}
\hline Ano & Recursos $=\mathrm{R} \$$ \\
\hline 2000 & $3.100 .000,00$ \\
\hline 2001 & $3.090 .000,00$ \\
\hline 2002 & $2.490 .000,00$ \\
\hline 2003 & $2.421 .491,00$ \\
\hline Total & $11.101 .491,00$ \\
\hline
\end{tabular}

Fonte: BRASIL. Governo Federal. Ministério da Defesa/SPEAI/DPE. Disponível em: <http://www.defesa.gov.br>. Acesso em: 12 nov. 2003.

Apesar dos problemas de otimização e eficiência nos gastos da Defesa, não procede a crítica segundo a qual os militares mantiveram uma grande influência no Estado, que lhes permitiu concentrar recursos, em detrimento do investimento em outras prioridades governamentais.

Com o decréscimo dos recursos alocados, os militares foram obrigados a responder com criatividade aos constantes cortes de verbas públicas. Uma das medidas tomadas, como revela a Tabela 11, foi a flexibilidade na aplicação do orçamento. Assim, a adoção de uma política de articulação com outras esferas do governo, com o estabelecimento de parcerias com organismos públicos e a iniciativa privada por intermédio de convênios, permitiu manter em condições mínimas o funcionamento institucional das ações, mormente de prefeituras da área da Calha Norte. Isso tornou possível a construção, a reforma e o reaparelhamento de inúmeros equipamentos urbanos. Por exemplo, no biênio 2000-2001, convênios com 24 prefeituras resultaram em obras nas comunidades carentes, especialmente no Estado do Amazonas. 


\section{O IMPACTO DA NOVA POLÍTICA DE DEFESA NACIONAL NO FINANCIAMENTO DO PCN}

Pode-se afirmar, então, que a revitalização do PCN, com a conseqüente elevação do montante de dinheiro público, foi motivada pelas exigências de implantação da nova PDN e pela criação do Ministério da Defesa? Poder-se-a dizer que sim.

A PDN incentiva a reorientação estratégica e geopolítica do Brasil para a região amazônica. Contudo, a investigação até aqui realizada demonstra que, de fato, não têm sido materializadas a contento as diretrizes traçadas, nao têm sido alcançadas as metas definidas. Lançada em 1996, somente em 2000 e 2002, a PDN terá um ligeiro acréscimo no aporte financeiro, como examinado no tópico anterior. O desafio do governo reformista é superar o hiato entre as promessas contidas na Nova PDN, o ajuste fiscal e as ambições do PPA. Há uma assimetria, portanto, entre os fundamentos da PDN e a vontade política de tornar efetivamente a Amazônia uma prioridade.

Não parece convincente, em princípio, que a unificação dos ministérios militares na Defesa tenha exercido alguma influência na determinação dos recursos. Mas é fato que a retomada do trabalho coincide com a aplicação do PPA 2000-2003, cujo objetivo era criar um ambiente macroeconômico favorável ao crescimento sustentável e, particularmente no que diz respeito à defesa, garantir a defesa nacional como fator de consolidação da democracia e do desenvolvimento.

O Plano foi instituído pela Lei n. ${ }^{\circ}$ 9.989, de 21 de julho de 2000, que cumpre as exigências legais do Decreto n. ${ }^{\circ} 2.829$, de 29 de outubro de 1998, o qual define as normas para a elaboração e a execução do PPA e dos orçamentos da União. No âmbito da política orçamentária do governo, o PPA 2000-2003 contém os valores por programas e os valores presumidos para o financiamento das ações do governo. Estabelece também a ação, a caracterização do produto, a unidade de medida, a meta vigente e a meta saldo. O Ministério da Defesa tem recebido um apoio importante, da Comissão de Defesa Nacional do Senado Federal, na sua busca de uma solução para o grave problema de cortes nos investimentos. Essa comissão tem agido, ininterruptamente, no sentido de pressionar por verbas extras para "salvar" o PCN.

O Relatório de Avaliação para o período de 2000 a 2003 apresenta os créditos orçamentários para cada programa e a ação executada pelo Governo Federal, no âmbito do PCN, além das metas e dos indicadores de resultados. O Plano também seguiu um cronograma bastante rígido (Quadro 1). 
Quadro 1: Etapas do PPA 2000-2003

\begin{tabular}{|ll|l|}
\hline \multicolumn{2}{|c|}{ Etapa } & Prazo \\
\hline 1 & Módulo de avaliação & Até 3/11/2000 \\
\hline 2 & Treinamento dos gerentes dos programas & 9 a 23/11/2000 \\
\hline 3 & $\begin{array}{l}\text { Treinamento dos gerentes de políticas } \\
\text { públicas de cada órgão setorial }\end{array}$ & 28 a 29/11/2000 \\
\hline 4 & Etapa 1: Avaliação dos programas pelos gerentes & até 29/12/2000 \\
\hline 5 & Etapa 2: Avaliação do órgão setorial & até 19/01/2001 \\
\hline 6 & $\begin{array}{l}\text { Etapa 3: Avaliação pelo Ministério do } \\
\text { Planejamento, Orçamento e Gestão }\end{array}$ & até 11/03/2001 \\
\hline 7 & $\begin{array}{l}\text { Validação do Relatório Preliminar de Avaliação } \\
\text { nos ministérios/órgãos setoriais }\end{array}$ & até 6/04/2001 \\
\hline 8 & $\begin{array}{l}\text { Encaminhamento à PR do primeiro Relatório de } \\
\text { Avaliação do PPA 2000-2003 }\end{array}$ & até 12/04/2001 \\
\hline $\begin{array}{l}\text { Encaminhamento ao Congresso Nacional do } \\
\text { primeiro Relatório de Avaliação do PPA 2000-2003 }\end{array}$ & \\
\hline
\end{tabular}

Fonte: BRASIL, 2000.

Antes de iniciar o exame meticuloso do PPA, é necessário precisar que, inicialmente, o PCN fazia parte do programa "Proteção da Amazônia". Somente a partir de 2002, ele passa a constar expressamente no tópico "Ministério da Defesa". Em 2000 e 2001, os recursos destinavam-se exclusivamente ao SIMPAM/SIVAM, que era - e é - prioritário para a vigilância da Amazônia. É com perplexidade que se constata (ver Tabela 9) que os valores liberados são absolutamente superiores às metas previstas no PPA. Embora seja significativo, o montante liberado em 2002 é ligeiramente inferior ao de 2000, e a soma de 2001 é inferior à desses dois anos, como se viu anteriormente (AUMENTO..., 2001, p. 8). Constata-se também que a lógica da linearidade do PPA, do Projeto de Lei Orçamentária Anual (PLOA) e da Lei Orçamentária Anual (LOA) não é respeitada, com exceção do ano de 2003.

Tabela 9 - Recursos previstos e liberados no orçamento do PPA 2000$2003-$ em R\$

\begin{tabular}{l|c|c|c|c}
\hline & 2000 & 2001 & 2002 & 2003 \\
\hline Previsto no PPA & $3.763 .000,00$ & $3.780 .900,00$ & $3.988 .500,00$ & $4.349 .000,00$ \\
\hline Previsto no PLOA & $2.881 .147,00$ & $5.763 .000,00$ & $6.840 .053,00$ & $14.328 .253,00$ \\
\hline Previsto na LOA & $24.981 .147,00$ & $36.940 .336,00$ & $44.790 .053,00$ & $42.445 .611,00$ \\
\hline Liberado & $29.246 .000,00$ & $16.047 .357,00$ & $26.247 .701,39$ & $?$ \\
\hline
\end{tabular}

Fonte: BRASIL, 2003. 
O valor liberado em 2000, abaixo do previsto, gerou, em 2001, uma série de críticas dos representantes dos comandantes militares. Essas críticas estão expressas na justificativa de cada programa. Em relação ao macroobjetivo 27 (exercício de 2001) - "garantir a defesa como fator de consolidação da democracia e do desenvolvimento" -, os militares manifestam inquietação com os constantes cortes no orçamento da defesa, que inviabilizou o cumprimento das metas previstas.

Assim, lê-se no programa "Adestramento e operações militares da Aeronáutica", do Comando da Aeronáutica:

Na alocação dos recursos do PPA 2000-2003 era previsto aumento de dotação orçamentária a partir de 2001, o que não se concretizou na Lei Orçamentária Anual - LOA. Os aportes em 2001 e 2002 permanecem abaixo do previsto. Dentro desta perspectiva, será difícil alcançar índices condizentes com uma Força Aérea operacional (BRASIL, 2000, p. 787).

Lê-se também no programa "Adestramento e operações militares da Marinha", do Comando da Marinha:

Em que pese todos os esforços da Marinha para alcançar os resultados apresentados, os sucessivos cortes orçamentários que vêm sendo impostos ao programa, poderão levar à degradação dos navios, aeronaves e meios dos fuzileiros navais que, em função de uma indesejável adequação aos recursos financeiros disponíveis, sofrerão alterações nas rotinas do Sistema de Manutenção Planejada - SMP e nas atribuições de prioridades resultando um menor índice de operacionalidade da Força Naval (BRASIL, 2000, p. 789).

Lê-se ainda no programa "Adestramento e operações militares do Exército", do Comando do Exército:

O contigenciamento dificultou a execução do programa, uma vez que o planejamento inerente a cada ação não foi executado na época oportuna. No entanto, com o descontigenciamento em novembro, o índice do programa evoluiu de maneira satisfatória, mantendo-se num patamar compatível com o desejado (BRASIL, 2000, p. 790).

Apesar das críticas aos cortes no orçamento da defesa, que prosseguem em 2002 e 2003 e dificultaram a continuidade desses e de outros programas, os objetivos das FFAA - defender o território nacional, manter a integridade territorial e do patrimônio público e manter a segurança das fronteiras políticas - foram alcançados, embora precariamente. 
Todavia, no programa de proteção da Amazônia, verifica-se uma certa melhora, embora nem todas as metas tenham sido alcançadas. Foram executadas as seguintes ações: implantação de mais de 80\% da infra-estrutura do SIVAM; integração de dezesseis órgãos federais e estaduais, dentro do conceito de parceria preconizada pelo Conselho Deliberativo do Sistema de Proteção da Amazônia (CONSIPAM); capacitação de 144 pessoas que atuarão diretamente no SIPAM e/ou firmarão interface com o sistema; implantação de 88\% da integração da base de dados do SIPAM (BRASIL, 2000, p. 805).

O volume de aportes, significativo em 2000 e menor, mas importante em 2002, permite afirmar que a retomada do financiamento não pode ser atribuída à nova PDN e à criação do Ministério da Defesa, porque os ensaios realizados pelo governo não representaram dividendos a mais para o Programa e para a fronteira política. Em vista disso, a PDN e o PPA, no que diz respeito à meta de gerar efeitos positivos na fronteira Norte, tornam insustentável a defesa da crítica da incapacidade do governo em arcar com as condições econômico-financeiras a fim de garantir suas necessidades e cumprir as obrigações constitucionais no âmbito dos projetos especificados: 1) construção de embarcação para controle e segurança da navegação fluvial; 2) implantação de infraestrutura básica nos municípios mais carentes; 3) implantação de unidades militares. Evidentemente, dado o passivo histórico do poder central na região, essas ações, ainda que positivas, estão distantes de representar, efetivamente, uma solução ótima. 


\section{CONSIDERAÇÕES FINAIS}

O Estado tem legitimidade para definir e executar um planejamento estratégico numa área da Região Amazônica, consagrada como de segurança nacional, com legislação específica para o uso do território. Trata-se da Faixa de Fronteira de 150km de largura.

Essa região apresenta características de área marrom ${ }^{6}$ : alta taxa de concentração urbana nas principais cidades da região, economia extrativista, inúmeras rotas de contrabando e tráfico de animais silvestres, madeira, minérios, peles, armas e cocaína (entre outros entorpecentes), administrações públicas municipais e estaduais falidas. Aqui, apesar dessas condições scoioeconômicas, o Estado cumpre, relativamente bem, seus deveres constitucionais na aplicação do dinheiro público, garantindo segurança na fronteira política a fim de diminuir a incerteza quanto aos riscos. O discurso é sempre o mesmo: o Estado tem a missão de defender o território soberano, de evitar a perda da soberania brasileira sobre a Amazônia. Portanto, os recursos aplicados no PCN responderiam às demandas econômicas e sociais da região e prerrogativas constitucionais.

Não está claro se a crise de financiamento e a falta de continuidade institucional do Programa deve-se à reforma do Estado e à dívida externa. Outros fatores explicam a letargia no desenvolvimento e na consolidação das atividades sociais, econômicas e na defesa e segurança da fronteira política. De acordo com o conjunto dos dados mostrados e a penetrante análise realizada com base no conceito de governança, o principal motivo da interrupção nos investimentos seria a vontade política de não tratar a região amazônica como prioridade de defesa, apesar do discurso em contrário contido nas peças orçamentárias. A reversão financeira materializa-se com a projeção do Avança Brasil e do PPA 20002003, quando são feitas ligeiras elevações na dotação orçamentária, apesar das metas não terem sido alcançadas a contento.

${ }^{6}$ O'Donnell (1993, p. 123-145) criou um modelo de análise para esse tipo de realidade sociopolítica. Ele supõe a criação de três áreas que correspondem a cores diferentes para expressar as diferentes dimensões do Estado. Todas as cores do mapa podem ser aplicadas tanto em perspectiva global, quanto num país em particular ou uma região dentro dele. A cor azul representa um alto grau de presença do Estado em todas as dimensões, isto é, as burocracias existem por toda parte e as leis são respeitadas, ou seja, o Estado enquanto lei realmente funciona e repousa em bases legítimas. A cor verde designa um alto grau de penetração do Estado territorial e uma presença mais baixa em termos funcionais (burocracia) de classe e do Estado enquanto lei. E a cor marrom, um nível muito baixo ou nulo nessas duas dimensões. Ou seja, as burocracias, quando existem, não atendem ao mínimo para o atendimento das demandas da cidadania e não há cumprimento da lei, ou, se a lei é cumprida, não atinge as camadas mais pobres da população. O autor cita o Nordeste e a Amazônia como exemplos da dimensão marrom do Estado. 


\section{REFERÊNCIAS}

AMADO, J. História e região: reconhecendo e construindo espaços. In: SILVA, M. A. da (Ed.). República em migalhas: história regional e local. São Paulo: Editora Marco Zero, CNPq, 1990. p. 7-15.

AUMENTO de militares é cortado. O Globo, Rio de Janeiro, 1 set. 2001. O País, Caderno 2, p. 8.

BOURDIEU, P. O poder simbólico. Rio de Janeiro: Editora Difel, 1989. 311p.

BRASIL. Governo Federal. Secretaria Geral do Conselho de Segurança Nacional. Desenvolvimento e segurança na região ao norte das calhas dos rios Solimões e Amazonas: Projeto Calha Norte. Brasília, DF, 1985. Mimeografado.

. Governo Federal. Ministério do Planejamento, Orçamento e Gestão. Plano Plurianual (PPA) 2000-2003: Avança Brasil. Relatório de Avaliação, exercício de 2000, Anexo I, Orçamento Fiscal e Seguridade. Brasília, 2000.

Governo Federal. Ministério do Planejamento, Orçamento e Gestão. Plano Plurianual (PPA) 2000-2003: Avança Brasil. Relatório Anual de Avaliação, exercício de 2001. Brasília, 2001.

. Congresso Nacional. Lei n. ${ }^{\circ} 10.524$, de 25 de julho de 2002, inciso IV, do Anexo das Informações Complementares ao Projeto de Lei Orçamentária de 2003.

Congresso Nacional. Orçamento da União. Exercício financeiro de 2002. Brasília, 2002a, v. VI.

Congresso Nacional. Orçamento da União. Orçamento de Investimento. Exercício financeiro de 2002. Brasília, 2002b, v. VI.

. Governo Federal. Ministério da Defesa. Projeto Calha Norte. Brasília, 2003. Disponível em: < http://www.defesa.gov.br>. Acesso em: 11 fev. 2003.

GOMES, P. C. O Conceito de Região e sua Discussão. In: CASTRO, I. E. (Org.). Geografia: conceitos e termos. Rio de Janeiro: Editora Bertrand Brasil, 1995. p. 49-76.

GONÇALVES, C. W. P. Amazônia: Amazônias. São Paulo: Editora Contexto, 2001. 
INSTITUTO BRASILEIRO DE GEOGRAFIA E ESTATÍSTICA. Anuário Estatístico de 2000. Disponível em: <http://www.ibge.gov.br>. Acesso em: 29 mar. 2003.

Indicadores de desenvolvimento sustentável: Brasil 2002. Rio de Janeiro, 2002. 170 p. (Estudos e Pesquisas. Informação Geográfica, n. 2).

KORB, L. Armas de destruição em massa: a experiência dos Estados Unidos. Revista Eletrônica da USIA, v. 4, n. 2, p. 8-14, set. 1999.

O'DONNELL, G. Sobre o Estado, a democratização e alguns problemas conceituais: uma visão latino-americana com uma rápida olhada em alguns países pós-comunistas. Novos Estudos CEBRAP, [S.l.], n. 36, p. 123-145, 1993.

OLIVEIRA FILHO, J. P. Segurança das fronteiras e o novo indigenismo: formas e linhagem do Projeto Calha Norte. Antropologia G Indigenismo: Projeto Calha Norte, militares, índios e fronteiras, Rio de Janeiro, Museu Nacional, n. 1, p. 16-33, 1990.

O MINISTRO da Defesa, Geraldo Quintão, quer transformar o Calha Norte em prioridade de Governo. O Globo, Rio de Janeiro, 9 jul. 2001. O País, Caderno 1, p. 7.

PEREIRA, C.; MUELLER, B. Comportamento estratégico em presidencialismo de coalizão: as relações entre Executivo e Legislativo na elaboração do orçamento brasileiro. Dados, Rio de Janeiro, v. 45, n. 2, p. 265301, 2002. Disponível em: <http://www.scielo.br/dados >. Acesso em: 12 out. 2003.

REZENDE, F. C. Descentralização, gastos públicos e preferências alocativas dos governos locais no Brasil (1980-1994). Dados, Rio de Janeiro, v. 40, n. 3, p. 413-440, 1997.

SILVEIRA, R. G. Região e história: questão de método. In: SILVA, M. A. da (Ed.). República em migalhas: história regional e local. São Paulo: Editora Marco Zero/CNPq, 1990. p. 17-42. 


\section{Consultas on line}

BRASIL. Ministério da Fazenda. Banco Central do Brasil (BACEN). Disponível em: <http://www.bcb.gov.br>. Acesso em: 21 jun. 2003.

Governo Federal. Ministério da Defesa. Disponível em: < http:// www.defesa.gov.br>. Acesso em: 02 fev. 2003.

Governo Federal. Ministério do Planejamento. Disponível em: <http://www.planejamento.gov.br>. Acesso em: 02 fev. 2003.

CENTRO DE ESTUdios NUEVA MAYORÍA. Disponível em: <http:// www.nuevamayoria.com>. Acesso em: 21 ago. 2003.

DEPARTAMENTO Intersindical de Estatística e Estudos Socioeconômicos. Disponível em: <http://dieese.gov.br>. Acesso em: 23 abr. 2003. 